\title{
I 4 The Relationship between signal intensity and myocardial gadolinium concentration for three $M R$ perfusion pulse sequences: implications for measuring absolute myocardial blood flow
} Daniel C Lee*, Nils P Johnson and Kathleen R Harris

\begin{abstract}
Address: Northwestern University Feinberg School of Medicine, Chicago, IL, USA
\end{abstract}
* Corresponding author

from I th $^{\text {th }}$ Annual SCMR Scientific Sessions

Los Angeles, CA, USA. I-3 February 2008

Published: 22 October 2008

Journal of Cardiovascular Magnetic Resonance 2008, I0(SuppI I):AI5 doi:I0.II86/I532-429X-I0-SI-AI5

This abstract is available from: http://jcmr-online.com/content/I0/SI/AI5

(c) 2008 Lee et al; licensee BioMed Central Ltd.

\section{Background}

Absolute myocardial blood flow (in $\mathrm{ml} / \mathrm{min} / \mathrm{g}$ ) can be calculated from CMR first-pass perfusion studies by modelbased deconvolution of the left ventricular blood pool and myocardial signal intensity-time curves. This technique is increasingly being applied to calculate myocardial blood flow in various cardiovascular diseases [1-3]. A basic assumption of the deconvolution technique is that signal intensity is proportional to gadolinium concentration in both the blood pool and myocardium. Dual-bolus [4] and dual-echo [5] techniques have been proposed to address the known nonlinear signal response of the blood pool to gadolinium. Based on phantom studies or signal response to escalating Gd dose, recent reports suggest that despite its low signal, the myocardial response to gadolinium is also nonlinear $[6,7]$. The myocardial signal response to myocardial gadolinium concentration needs to be defined for common perfusion pulse sequences to guide the appropriate application of absolute perfusion measurements by deconvolution.

\section{Purpose}

We sought to define the relationship between myocardial signal response and myocardial gadolinium concentration for three pulse sequences: 1) saturation recovery-prepared segmented echo-planar-imaging (SR-EPI), 2) saturation recovery-prepared turbo fast low-angle shot (SR-FLASH), and 3) inversion recovery-prepared singleshot steady-state free-precession (IR-SSFP).

\section{Methods}

Imaging was performed in two purpose-bred hounds, chronically instrumented with left atrial, right atrial, and aortic catheters on a $1.5 \mathrm{~T}$ clinical MR scanner (Siemens Sonata). As regional gadolinium concentration can be calculated from the longitudinal relaxation rate (1/T1), cardiac $\mathrm{T} 1$ can therefore be measured from $\mathrm{T} 1$ mapping performed using a modified Look-Locker technique (MOLLI) [8]. During a constant slow infusion of Gd, a single mid-ventricular short axis slice was alternately imaged for 1) signal intensity by SR-EPI, SR-FLASH, or IRSSFP and 2) T1 mapping (MOLLI). Infusion experiments were performed with an infusion rate of $0.5 \mathrm{mmol} / \mathrm{min}$ in order to span the myocardial signal range expected in response to a $0.05 \mathrm{mmol} / \mathrm{kg}$ IV bolus. Signal intensity values were normalized to correct for coil inhomogeneity and the baseline signal. The increase in normalized signal intensity and gadolinium concentration were plotted against the time of infusion. The signal intensity and gadolinium concentration curves as functions of time were interpolated using a cubic spline technique to generate a parameterized signal intensity response curve as a function of gadolinium concentration.

\section{Results}

The relationship between signal intensity and gadolinium concentration was nonlinear for SR-EPI and SR-FLASH, resulting in underestimation of gadolinium concentrations higher than $0.5 \mathrm{mmol} / \mathrm{L}$. IR-SSFP was linear over the full range of gadolinium concentration tested. At a gado- 


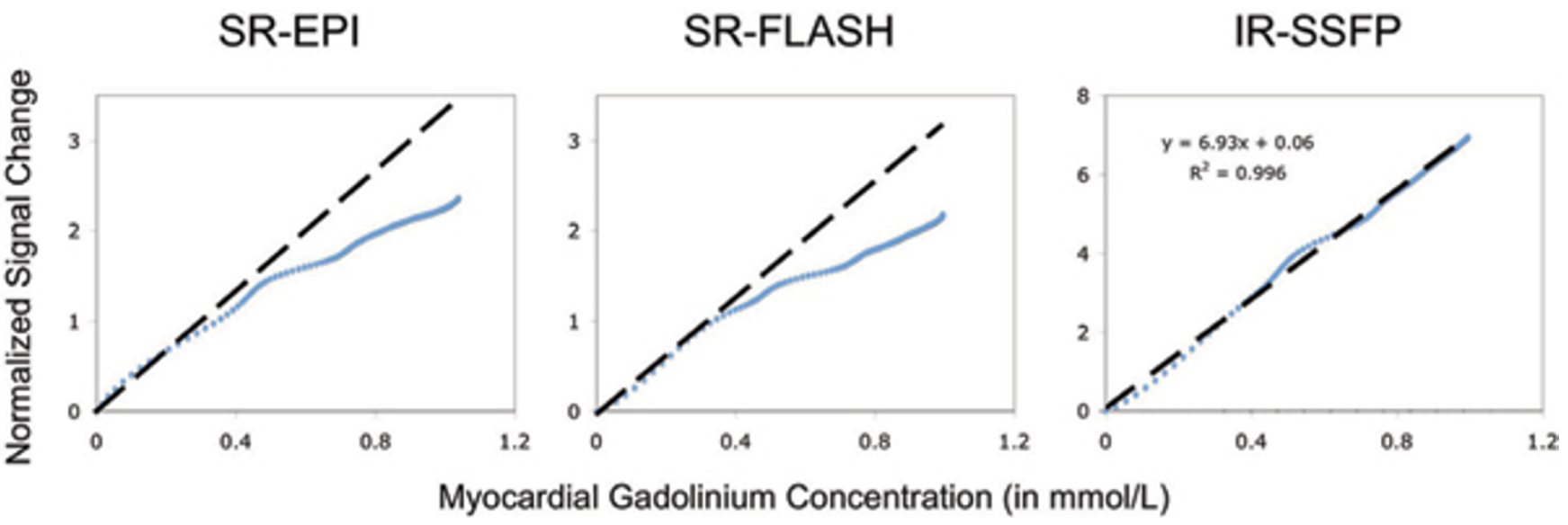

Figure I

The relationship between myocardial signal intensity and gadolinium concentration affects absolute blood flow calculation. It is linear for inversion recovery steady state free precession but nonlinear for saturation recovery echo planar imaging and turbo fast low angle shot perfusion sequences.

linium concentration of $1 \mathrm{mmol} / \mathrm{L}$, the relative signal increase over baseline for SR-EPI, SR-FLASH, and IR-SSFP were $2.4,2.2$, and 7.0 respectively. Figure 1 illustrates the signal response for each pulse sequence.

\section{Conclusion}

The relationship between myocardial signal intensity and gadolinium concentration depends on the first-pass perfusion pulse sequence used. IR-SSFP demonstrates excellent myocardial signal enhancement and is linear over the range expected for a $0.05 \mathrm{mmol} / \mathrm{kg}$ bolus. Over the same range, SR-EPI and SR-FLASH exhibit less robust myocardial signal enhancement and a nonlinear response to gadolinium concentration. The nonlinear signal response of SR-EPI and SR-FLASH needs to be accounted for to avoid underestimation of absolute myocardial blood flow by model-based deconvolution.

\section{References}

I. Selvanayagam, et al.: Circulation 2005, I I 2:3289-3296.

2. Petersen, et al.: Circulation 2007, I I 5:24I 8-2425.

3. Wang, et al.: J Am Coll Cardiol 2006, 47:565-572.

4. Christian , et al.: Radiology 2004, 232:677-684.

5. Gatehouse, et al.: J Magn Reson Imaging 2004, 20:39-45.

6. Weber , et al.: J Magn Reson Imaging 2007, 26:569-579.

7. Utz, et al.: J Magn Reson Imaging 2007, 25: I I 3 I-I I 35.

8. Messroghli, et al.: Magn Reson Med 2004, 52:|4|-|46.
Publish with Bio Med Central and every scientist can read your work free of charge

"BioMed Central will be the most significant development for disseminating the results of biomedical research in our lifetime. "

Sir Paul Nurse, Cancer Research UK

Your research papers will be:

- available free of charge to the entire biomedical community

- peer reviewed and published immediately upon acceptance

- cited in PubMed and archived on PubMed Central

- yours - you keep the copyright

Submit your manuscript here:

http://www.biomedcentral.com/info/publishing_adv.asp
BioMedcentral 